\title{
Refractive outcome of prethreshold retinopathy of prematurity treated by diode laser: follow-up at 5 years
}

This article was published in the following Dove Press journal:

Clinical Ophthalmology

22 September 2015

Number of times this article has been viewed

\section{Phuoc Huu Nguyen ${ }^{1,2}$ \\ Caroline Catt ${ }^{2}$ \\ Tinh Xuan Nguyen ${ }^{3}$ \\ Van Trong Pham ${ }^{4,5}$}

'Department of Ophthalmology, Thanhhoa Paediatrics Hospital,

Thanhhoa City, Vietnam; ${ }^{2}$ Save Sight Institute and Discipline of Clinical Ophthalmology, University of Sydney, NSW, Australia; ${ }^{3}$ Paediatrics Department, Vietnam National Ínstitute of Ophthalmology, ${ }^{4}$ Ophthalmology Department, Hanoi Medical University, ${ }^{5}$ Oculoplastics and Cosmesis Department, Vietnam National Ínstitute of Ophthalmology, Hanoi, Vietnam
Correspondence: Phuoc Huu Nguyen Thanhhoa Paediatrics Hospital, Quang Trung 3 Street, Dong Ve Ward, Thanhhoa City, Vietnam Email bacsiphuoc@gmail.com
Background: The purpose of this study was to evaluate the refraction of eyes treated with diode laser photocoagulation for prethreshold retinopathy of prematurity (ROP) at a mean of 5 years after treatment.

Materials and methods: Fifty infants with prethreshold ROP treated with diode laser at Hanoi Childrens' Hospital during the period 2008 to 2009 were reviewed. Refractive error was identified by cycloplegic refraction with Cyclogyl 1\%. Myopia was divided into two categories based on magnitude: high myopia (more than $-5.00 \mathrm{D}$ ) and low myopia (between 0 and -5.00 D). Hypermetropia was subdivided into low hypermetropia (between 0 and +5.00 D) and high hypermetropia (greater than $+5.00 \mathrm{D}$ ). Astigmatism was classified as high if $>2.00 \mathrm{D}$. Eyes with media opacification that interferes with retinoscopy were excluded. The refractive outcome was correlated with birth weight and gestational age. The anatomical and visual outcomes were recorded.

Results: One hundred eyes from 50 infants were included in the study. The mean birth weight was $1,426.4 \mathrm{~g}$ and the mean gestational age was 29.88 weeks. After 5 years of follow-up, the average spherical equivalent for 100 eyes was $-2.87 \mathrm{D}$. On cycloplegic retinoscopy, high myopia (more than $-5.00 \mathrm{D}$ ) was seen in $32 \%$ of eyes. Twenty $(20 \%)$ eyes had nonsignificant hypermetropia, and high hypermetropia $($ more $+5.00 \mathrm{D})$ was seen in only one eye $(1 \%)$. The prevalence of astigmatism and high astigmatism (more than $-2.00 \mathrm{D}$ ) was $79 \%$ and $49 \%$, respectively. Three infants $(6 \%)$ had esotropia and two infants $(4 \%)$ had exotropia. None of the infants had nystagmus.

Conclusion: The majority of patients who underwent diode laser therapy for prethreshold ROP had favourable anatomical and visual outcomes. High refractive error is common and may be the cause of visual impairment.

Keywords: refractive outcome, myopia, hypermetropia, astigmatism

\section{Introduction}

Retinopathy of prematurity (ROP) is one of the leading causes of infant blindness and visual impairment worldwide. The Cryotherapy for Retinopathy of Prematurity study has established the benefit of treatment for threshold ROP in reducing the risk of blindness. ${ }^{1,2}$ Another report also showed that cryotherapy in threshold ROP contributes to the development of myopia and that laser photocoagulation, in comparison, produces less myopic shift. ${ }^{3}$ In recent times, laser photocoagulation has largely replaced cryotherapy as the established treatment modality for ROP. ${ }^{4,5}$ The guidelines for the treatment of ROP have changed after the Early Treatment for Retinopathy of Prematurity (ETROP) study, which used a complex algorithm to identify patients with prethreshold ROP and having a high risk for progression. ${ }^{6-9}$ 
At present, in Vietnam, advances in neonatology allow survival of children with extremely low gestational age and weight at birth, leading to an increase in the number of patients with ROP. Refractive error is a known complication of ROP and its treatment, and is a common cause of vision impairment in children. It is also treatable. Therefore, we initiated this study to evaluate the refraction of eyes treated with diode laser photocoagulation for prethreshold ROP at a mean of 5 years after treatment.

\section{Materials and methods}

The study was approved by the Vietnam National Institute of Ophthalmology and parents provided written informed consent prior to infants' enrollment into the study. We identified all infants treated for ROP according to the criteria defined by ETROP from the operating theater register at the hospital. All laser procedures in preterm infants were conducted in the hospital operating theater during the study period (2008-2009).

Children who were born prematurely and attended the eye clinic at Hanoi Children's Hospital following treatment for prethreshold ROP with diode laser were included in the study and followed up for 5 years. The screening guidelines from the Vietnam Ministry of Health include all infants with birth weight of $\leq 1,800 \mathrm{~g}$ and/or gestational age $\leq 33$ weeks. The laser procedure was carried out in the operating theater in the presence of the neonatologist. The entire avascular retina, from the ridge to the ora serrata, was treated in a near confluent manner using a diode laser indirect ophthalmoscope. The laser treatment was performed by trained vitreoretinal specialists with experience in the use of the indirect diode laser. If the follow-up examinations showed persistent "plus" disease with the presence of active extraretinal proliferation, such eyes were retreated to cover any areas of undertreatment. Once the ROP showed regression, the infants were followed up every 6-12 months. During each visit, the infants were examined for the pattern of fixation, presence of strabismus, and cycloplegic refraction with cyclopentolate $1 \%$ eye drops. Fundus examination is done by indirect ophthalmoscopy. The best corrected visual acuity in each eye was checked with Cardiff cards at a $50 \mathrm{~cm}$ distance in the preverbal age group, and the Snellen equivalent was noted. In those children who were able to communicate verbally, visual acuity was measured with the Snellen visual acuity chart.

All infants underwent confluent laser treatment (spots less than half burn width apart) with a diode laser (Iris Medical Oculight SL, $810 \mathrm{~nm}$ infrared laser; Iris Medical Inc, Mountain View, CA, USA). Treatment details were analyzed, including the type of laser used, number of laser spots, number of laser sessions, and time required for regression of disease. Unfavorable outcomes included: a posterior retinal fold involving the macula, a retinal detachment involving the macula, or retrolental tissue or mass obscuring the view of the posterior pole.

The case charts were reviewed to collect data regarding sex, gestational age at birth, birth weight, whether a product of single or multiple pregnancy, number of ventilated days, presence of intraventricular hemorrhage, and sepsis. The eye, zone of ROP, the circumferential extent of extraretinal proliferation, postconception age at treatment, and need for retreatment were noted. Details of further vitreoretinal surgeries, if any, and their results were noted. The anatomical status of the retina, best corrected visual acuity, spherical equivalent (SE) refraction (spherical value plus half the cylinder value) in each eye, presence of strabismus, and duration of follow-up in months were recorded.

Myopia was divided into two categories based on magnitude: high myopia ( $>5 \mathrm{D})$ and low myopia (0-5 D). Hypermetropia was defined as $>0$ and subdivided into low hypermetropia (0-5 D) and high hypermetropia ( $>5 \mathrm{D})$. Astigmatism and high astigmatism were defined as plus cylinder of $\geq 1 \mathrm{D}$ and $\geq 2 \mathrm{D}$, respectively.

This was a long-term, descriptive study without a control group such as cryotherapy or other photocoagulation therapy, and may indicate the superiority of the diode laser applied in Vietnam.

\section{Statistical analysis}

Statistical analysis was done using Statistical Package for the Social Sciences version 16.0 software for Windows (IBM Corporation, Armonk, NY, USA).

\section{Results}

Fifty infants met the inclusion criteria for the study. Their mean birth weight was $1,426.40$ (range: $800-1,750$ ) g. Thirtyseven infants (74\%) had a birth weight $>1,250 \mathrm{~g}$. The mean gestational age was 29.88 (range: 27-32) weeks.

One hundred eyes from these 50 infants were treated for prethreshold ROP. Eighty-two (82\%) eyes had zone 2 disease

Table I Characteristics of the study population

\begin{tabular}{lll}
\hline $\begin{array}{l}\text { Total number of babies } \\
\text { (male, female) }\end{array}$ & $50(22-28)$ & \\
Average gestational age (weeks) & $29.88(27-32)$ & \\
Average weight at birth $(\mathrm{g})$ & $\mathrm{I}, 426.40(800-1,750)$ & \\
\hline Refraction at 5 years & Right eye & Left eye \\
Average SE (range) & $-2.75(-13$ to +5$)$ & $-3.20(-12$ to +4$)$ \\
Average astigmatism & $-1.70 \mathrm{D}$ & $-1.72 \mathrm{D}$ \\
\hline
\end{tabular}

Abbreviations: SE, spherical equivalent; $D$, diopters. 
Table 2 Spherical equivalent in right and left eyes $(n=100)$

\begin{tabular}{llll}
\hline SE & Right eye & Left eye & Total \\
\hline$\geq+5.0$ & None & None & 0 \\
+2.5 to +5 & 5 & 3 & 8 \\
0.25 to +2.25 & 7 & 6 & 13 \\
0 to -2.25 & 14 & 15 & 29 \\
-2.5 to -4.75 & 7 & 11 & 18 \\
-5.0 to -10 & 16 & 14 & 30 \\
$>-10$ & 1 & 1 & 2 \\
Total & 50 & 50 & 100 \\
\hline
\end{tabular}

Notes: All values are measure in Diopters. SE are presented in a range.

Abbreviation: SE, spherical equivalent.

and $15(15 \%)$ eyes had zone 1 disease. The mean number of total clock hours of ROP was $8.94 \pm 2.73$ (range: $5-12$ ). The

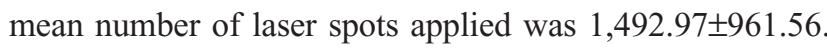
Nine eyes required retreatment. The mean time to regression of ROP following treatment was $4.92 \pm 2.45$ (range: 2-18) weeks (Table 1).

Table 2 shows the distribution of refractive errors in the right and left eyes. On cycloplegic retinoscopy, the average SE for 100 eyes was $-2.87 \mathrm{D}$ (range: -13 to $+5 \mathrm{D}$ ). The average SE in the right and left eyes was $-2.75 \mathrm{D}$ (range: -13 to $+5 \mathrm{D}$ ) and $-3.20 \mathrm{D}$ (range: -12 to $+4 \mathrm{D}$ ), respectively. Twenty-seven $(27 \%)$ eyes had low myopia $(<5 \mathrm{D})$ with a range: $-0.25 \mathrm{D}$ to $-4.75 \mathrm{D}$. High myopia $(>5.0 \mathrm{D})$ was seen in $32(32 \%)$ eyes. Twenty (20\%) eyes had insignificant hyperopia (range: +0.25 to $+4.00 \mathrm{D}$ ), and high hyperopia $(>5.00 \mathrm{D})$ was seen in only one (1\%) eye. Twenty $(20 \%)$ eyes had no refractive error.

Considering the right and left eyes separately, the SE of the right eye ranged from $-13.00 \mathrm{D}$ to $+5.00 \mathrm{D}$ (mean $-2.75 \mathrm{D}$ ). In the left eye, it ranged from $-12.00 \mathrm{D}$ to $+4.00 \mathrm{D}$ (mean $-3.20 \mathrm{D}$ ). Applying the Wilcoxon's test to these data, no statistically significant $(P<0.05)$ difference was found between the eyes (Table 2).

The prevalence of astigmatism and high astigmatism $(>2.00 \mathrm{D})$ in our study was $79 \%$ and $49 \%$, respectively. The average astigmatism was $1.65 \mathrm{D}$. The lowest level of astigmatism was $0.50 \mathrm{D}$ and the highest level was $6.50 \mathrm{D}$.

Corresponding to each birth weight group, the most common refractive error was myopia. The proportion of myopia in the $800-1,250 \mathrm{~g}$ birth weight group was $61.53 \%$; in the $1,251-1,500 \mathrm{~g}$ group it was $62.5 \%$ and in the $1,501-1,750 \mathrm{~g}$ group it was $55.81 \%$. The difference was statistically significant $(P<0.05)$, which suggests that the lower the birth weight, the higher the prevalence of myopia and high myopia (Table 3).

The proportion of myopia in the 27-28-week gestation group was higher than the two groups of gestational age, 29-30 weeks and 31-32 weeks. At 5-year follow-up, all eyes had a favorable anatomical outcome. None of the eyes showed structural posterior pole sequelae such as narrowing of arcades, disc drag, or macular drag. Peripheral ocular changes, namely, vitreous membranes and peripheral tractional retinal detachment, were not observed in any eye (Table 4).

Three infants (6\%) had esotropia and two infants (4\%) had exotropia. None of the five infants with strabismus had anisometropic amblyopia, as the refractive error was similar for both eyes. None of the infants had nystagmus.

\section{Discussion}

In the present study, nearly one-third of the infants had a birth weight greater than $1,251 \mathrm{~g}$. Treatable ROP in infants with $>1,250 \mathrm{~g}$ birth weight is not uncommon in the developing world. In contrast, most reports from Western centers and developed countries focus on ROP in extremely premature infants of $<1,250 \mathrm{~g}$ birth weight ${ }^{10,11}$ (Table 5). The mean birth weight of infants in the present study was $1,426.40 \mathrm{~g}$, which was much higher than the $703 \mathrm{~g}$ in the ETROP cohort. ${ }^{8}$ The mean gestational age of infants in the present study was 29.88 weeks, which was higher than the 25 weeks for the ETROP cohort. ${ }^{8}$ Weight and gestational age in our study were similar to those in a previous study by a Vietnamese pediatric ophthalmologist, but higher than those reported by overseas authors, especially those from developed countries ${ }^{3,11-15}$ (Table 5).

In our study, the most common refractive error was myopia, with $59 \%$ of children being affected, while $21 \%$ were affected by hyperopia. Thus, the prevalence of refractive error in the study was $80 \%$. It is difficult to compare different studies regarding the refractive outcome. When reviewing the

Table 3 Correlation of birth weight and refraction

\begin{tabular}{|c|c|c|c|c|c|c|}
\hline \multirow{2}{*}{$\begin{array}{l}\text { Birth weight (g) } \\
\text { Refraction }\end{array}$} & \multicolumn{2}{|c|}{$800-1,250$} & \multicolumn{2}{|c|}{$I, 25 I-I, 500$} & \multicolumn{2}{|c|}{$I, 50 I-I, 750$} \\
\hline & $\mathbf{n}$ & $\%$ & $\mathbf{n}$ & $\%$ & $n$ & $\%$ \\
\hline Myopia & 16 & 61.53 & 20 & 62.5 & 24 & 55.81 \\
\hline Hypermetropia & 9 & 34.61 & 2 & 6.25 & 9 & 20.93 \\
\hline Emmetropia & I & 3.86 & 10 & 31.25 & 10 & 23.26 \\
\hline Total & 26 & 100 & 32 & 100 & 43 & 100 \\
\hline
\end{tabular}


Table 4 Correlation of gestational age and refraction

\begin{tabular}{|c|c|c|c|c|c|c|}
\hline \multirow{2}{*}{$\begin{array}{l}\text { Refraction } \\
\text { Gestational age (weeks) }\end{array}$} & \multicolumn{2}{|c|}{$27-28$} & \multicolumn{2}{|c|}{ 29-30 } & \multicolumn{2}{|c|}{$31-32$} \\
\hline & $n$ & $\%$ & $n$ & $\%$ & $n$ & $\%$ \\
\hline Myopia & 17 & 77.27 & 23 & 53.48 & 20 & 58.82 \\
\hline Hypermetropia & 2 & 9.09 & 12 & 27.91 & 6 & 17.65 \\
\hline Emmetropia & 3 & 13.64 & 8 & 18.61 & 8 & 23.53 \\
\hline Total & 22 & 100 & 43 & 100 & 34 & 100 \\
\hline
\end{tabular}

literature on refractive error in children with ROP, we found that the prevalence of myopia differed between studies, with a range from $52.2 \%$ to $77 \%{ }^{11,13,16,17}$ (Table 6).

According to some authors, high myopia is more common in children with ROP than in children without ROP. The study by Quinn et al reported a high myopia rate of 34\% at 2 years and a rate of $37.9 \%$ among 3 -year-old children. ${ }^{6}$ Our study found a high myopia rate of $32 \%$. The prevalence of high hypermetropia in the present study was only $1 \%$. Holmstrom et al also reported a low prevalence of hypermetropia of $4.4 \%$ at age 2.5 years. ${ }^{18}$

The prevalence of astigmatism and high astigmatism in our study was lower than that reported in the study by Yang et al, which was 98\% for astigmatism and 50\% for high astigmatism. ${ }^{19}$ However, the follow-up duration in that study was longer ( 9 years). Other studies also suggested that the prevalence of astigmatism was $40 \%$ at 3 years and $53.7 \%$ at 6 years..$^{20,21}$

The mean SE in our study was $-2.87 \mathrm{D}$, which was similar to the value of $-2.33 \mathrm{D}$ reported by McLoone et al. ${ }^{22}$ Differences in the mean SE values reported by different authors can be explained by differences in sample size, severity of ROP, method of treatment, and follow-up duration.

Only five $(10 \%)$ of the 50 infants in the present study had strabismus. This rate of strabismus was lower than $28.5 \%$ recently reported for eyes undergoing laser treatment at threshold. ${ }^{23}$ Other authors reported the percentage of strabismus to be $22 \%$ in children with ROP. ${ }^{24}$ The low rate of strabismus in the present study may be attributed to a short follow-up duration, predominant symmetric presentation, and regression without sequelae in both eyes.

There are a number of limitations in this study. The present study was retrospective in nature, which introduced inherent observation and inclusion bias. The study also lacked a control group. Another limitation of the study is its short follow-up duration.

In summary, we have reported the refractive outcome for babies treated for prethreshold ROP in a subset of Vietnamese infants who were heavier and older than those previously reported. Prethreshold ROP in these infants was milder and regressed without any retinal residual of ROP. Despite a normal anatomical outcome, a significant proportion (59\%) of eyes developed myopia. This refractive error needs to be followed up and treated where appropriate to optimize the visual potential and outcomes in children.

\section{Acknowledgments}

Phuoc Huu Nguyen is indebted to many people who have helped and encouraged him during the course of this study.

The authors thank Dr Mai Quoc Tung for manuscript reading. They also would like to thank all doctors and nurses at Vietnam National Institute of Ophthalmology and Hanoi Children Hospital for their generous help and encouragement and the library of the University of Sydney for providing the authors with free access to necessary references. Phuoc Huu Nguyen would like to express how he is truly grateful to his parents for their immeasurable love and care and for always encouraging him to explore his potential and pursue his dreams.

Table 5 Comparison of studies

\begin{tabular}{|c|c|c|c|c|}
\hline Study & Year & Country & MBW (g) & Mean GA (weeks) \\
\hline Axer-Siegel et al" & 2008 & Israel & 833.9 & 26 \\
\hline Lee et $\mathrm{al}^{12}$ & 2004 & Australia & 770 & 25.5 \\
\hline Knight-Nanan and O'Keefe ${ }^{3}$ & 1996 & Ireland & 918 & 26.77 \\
\hline Al-Otaibi et al ${ }^{13}$ & 2012 & Saudi Arabia & $896.9 \pm 33.5 *$ & $26.5 \pm 3.1^{*}$ \\
\hline Dhawan et $\mathrm{al}^{14}$ & 2008 & Indian & $882.2 \pm 265^{*}$ & $26.4 \pm 2.3^{*}$ \\
\hline Nguyen ${ }^{15}$ & 2007 & Vietnam & $1,474.4 \pm 250.3^{*}$ & $31.82 \pm 1.97 *$ \\
\hline Present study & 2014 & Vietnam & $\mathrm{I}, 426.40$ & 29.88 \\
\hline
\end{tabular}

Note: *Data are presented as mean \pm standard deviation

Abbreviations: GA, gestational age; MBW, mean birth weight. 
Table 6 Refractive error prevalence by other authors

\begin{tabular}{lllll}
\hline Author & Mean follow-up (years) & Eyes $(\mathbf{n})$ & Myopia & Hypermetropia \\
\hline Axer-Siegel et al"1 & 3 & 194 & $55.2 \%$ & $*$ \\
Katoch et al $^{16}$ & 3.5 & 76 & $26.1 \%$ & $*$ \\
Nguyen & 5 & 100 & $71.8 \%$ & $23.1 \%$ \\
Al-Otaibi et al $^{13}$ & $5.2 \pm 2.5^{\wedge}$ & 114 & $64 \%$ & $29 \%$ \\
Yang et al & 9 & 60 & $93 \%$ & $*$ \\
Present study & 5 & 100 & $59 \%$ & $21 \%$ \\
\hline
\end{tabular}

Notes: *Not available in the study. 'Data are presented as mean \pm standard deviation.
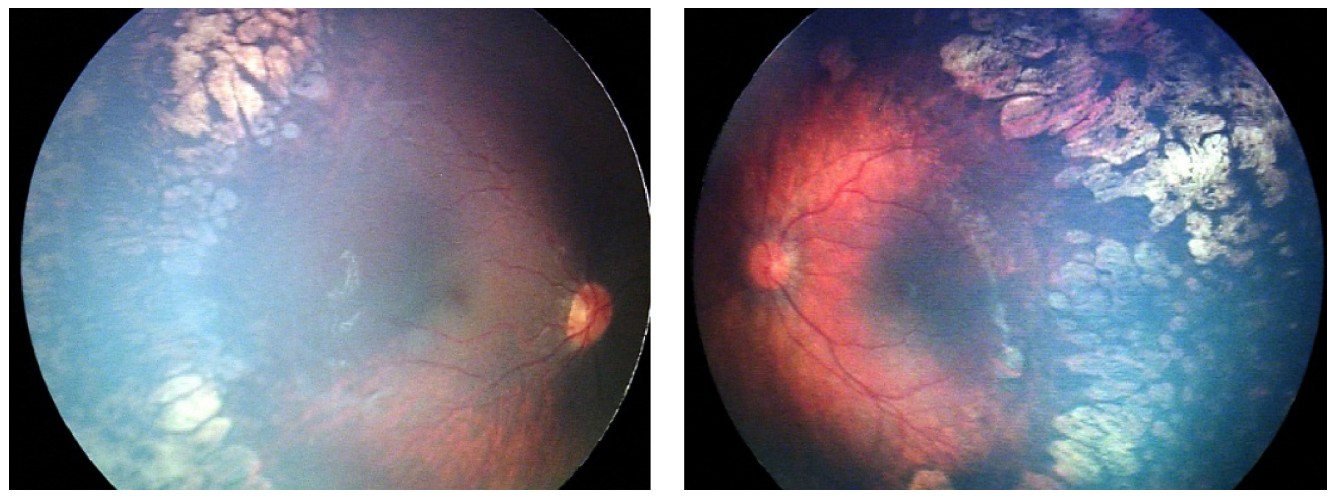

Figure I A male infant who was born at 29 weeks' gestation and of birth weight I.450 g. OU: ROP stage 2 and 3, zone I, with plus disease. ROP regressed bilaterally after laser treatment. Refraction at 65 months of age: OD, $-7.25 \mathrm{D} /-3.50 \mathrm{D}$, axis II degrees; OS, $-6.50 \mathrm{D} /-2.75$, D axis 170 degrees.

Abbreviations: ROP, retinopathy of prematurity; OD, oculus dexter; OU, oculus uterque; OS, oculus sinister.
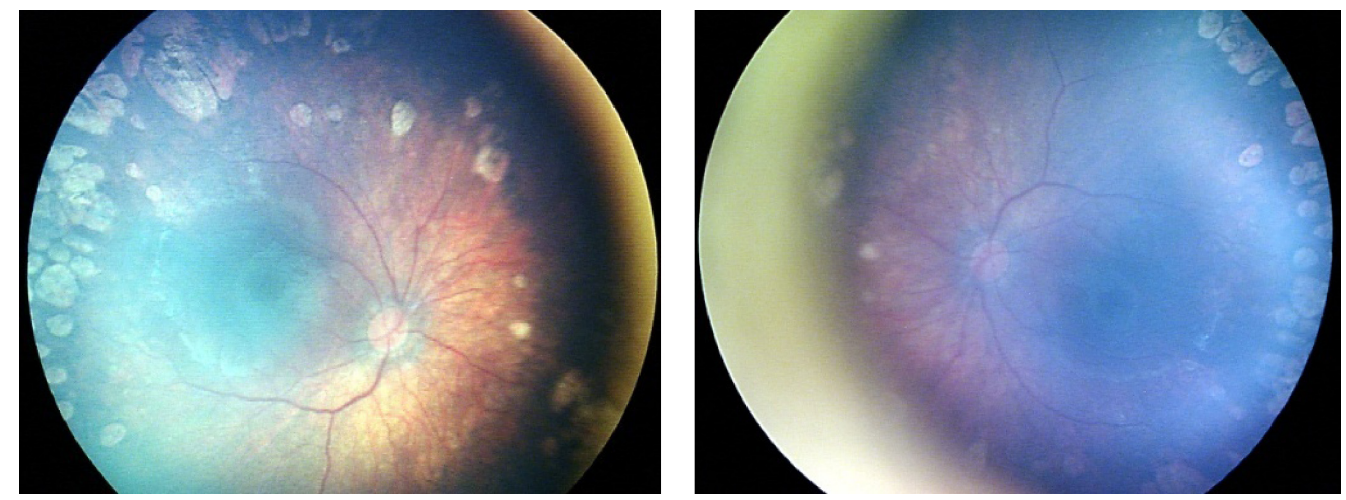

Figure $2 \mathrm{~A}$ female infant who was born at $3 \mathrm{I}$ weeks' gestation and of birth weight $1.600 \mathrm{~g}$. OU: ROP stage 2, zone I, with plus disease. ROP regressed bilaterally after laser treatment. Refraction at 62 months of age: OD, $-3.00 \mathrm{D} /-1.75 \mathrm{D}$, axis 0 degrees; OS, $-2.50 /-2.00$, axis 180 degrees.

Abbreviations: ROP, retinopathy of prematurity; OD, oculus dexter; OU, oculus uterque; OS, oculus sinister.
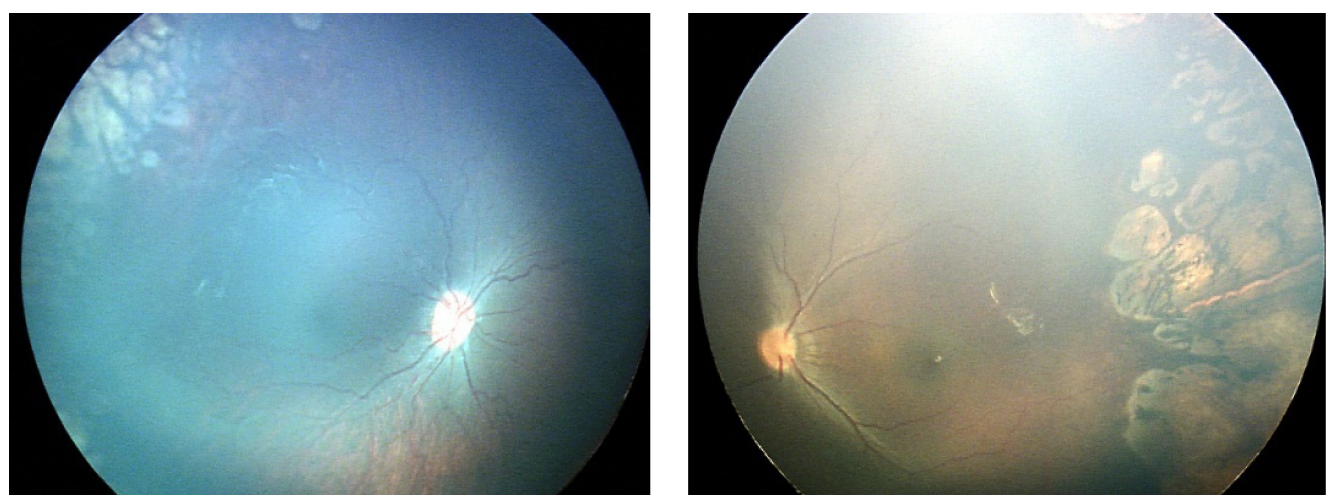

Figure 3 A male infant who was born at 31 weeks' gestation and of birth weight $1.200 \mathrm{~g}$. OU: ROP stage 2, zone 2, with disease. Regression of retinopathy of prematurity after laser treatment. Refraction at 61 months of age. OD, $-2.50 \mathrm{D} /-1.00 \mathrm{D}$, axis 0 degrees; OS, $-4.75 \mathrm{D} /-2.25 \mathrm{D}$, axis 180 degrees.

Abbreviations: ROP, retinopathy of prematurity; OD, oculus dexter; OU, oculus uterque; OS, oculus sinister. 


\section{Author contributions}

All authors contributed toward data analysis, drafting and critically revising the paper and agree to be accountable for all aspects of the work.

\section{Disclosure}

The authors report no conflicts of interest in this work.

\section{References}

1. Cryotherapy for Retinopathy of Prematurity Cooperative Group. Multicenter Trial of Cryotherapy for Retinopathy of Prematurity: ophthalmological outcomes at 10 years (2001). Arch Ophthalmol. 2001; 119(8):1110-1118.

2. [No authors listed]. Multicenter trial of cryotherapy for retinopathy of prematurity: preliminary results. Cryotherapy for Retinopathy of Prematurity Cooperative Group. Pediatrics. 1988;81(5):697-706.

3. Knight-Nanan DM, O'Keefe M. Refractive outcome in eyes with retinopathy of prematurity treated with cryotherapy or diode laser: 3 years follow up. Br J Ophthalmol. 1996;80(11):998-1001.

4. Yang CM. Diode laser photocoagulation for retinopathy of prematurity. J Formos Med Assoc. 1995;94(1-2):56-59.

5. McNamara JA, Tasman W, Vander JF, Brown GC. Diode laser photocoagulation for retinopathy of prematurity. Preliminary results. Arch Ophthalmol. 1992;110(12):1714-1716.

6. Quinn GE, Dobson V, Davitt BV, et al. Progression of myopia and high myopia in the early treatment for retinopathy of prematurity study: findings to 3 years of age. Ophthalmology. 2008;115(6):1058-1064. e1.

7. Hardy RJ, Good WV, Dobson V, et al. Multicenter trial of early treatment for retinopathy of prematurity: study design. Control Clin Trials. 2004;25(3):311-325.

8. Early Treatment For Retinopathy Of Prematurity Cooperative Group. Revised indications for the treatment of retinopathy of prematurity: results of the early treatment for retinopathy of prematurity randomized trial. Arch Ophthalmol. 2003;121(12):1684-1694.

9. Good WV; Early Treatment for Retinopathy of Prematurity Cooperative Group. Final results of the Early Treatment for Retinopathy of Prematurity (ETROP) randomized trial. Trans Am Ophthalmol Soc. 2004; 102:233-248

10. Choo MM, Martin FJ, Theam LC, U-Teng C. Retinopathy of prematurity in extremely low birth weight infants in Malaysia. $J$ AAPOS. 2009;13(5):446-449.
11. Axer-Siegel R, Maharshak I, Snir M, et al. Diode laser treatment of retinopathy of prematurity: anatomical and refractive outcomes. Retina. 2008;28(6):839-846.

12. Lee GA, Hilford DJ, Gole GA. Diode laser treatment of pre-threshold and threshold retinopathy of prematurity. Clin Experiment Ophthalmol. 2004;32(2):164-169.

13. Al-Otaibi AG, Aldrees SS, Mousa AA. Long term visual outcomes in laser treated threshold retinopathy of prematurity in Central Saudi Arabia. Saudi J Ophthalmol. 2012;26(3):299-303.

14. Dhawan A, Dogra M, Vinekar A, Gupta A, Dutta S. Structural sequelae and refractive outcome after successful laser treatment for threshold retinopathy of prematurity. J Pediatr Ophthalmol Strabismus. 2008;45(6):356-361.

15. Nguyen XT. Clinical features and initial application of laser treatment for retinopathy of premature. PhD dissertation. Hanoi, Vietnam: Hanoi Medical University; 2007.

16. Katoch D, Sanghi G, Dogra MR, Beke N, Gupta A. Structural sequelae and refractive outcome 1 year after laser treatment for type 1 prethreshold retinopathy of prematurity in Asian Indian eyes. Indian J Ophthalmol. 2011;59(6):423-426.

17. Dinh TT. Five years results of laser treatment for retinopathy of prematurity. Master's thesis. Hanoi, Vietnam: Hanoi Medical University; 2011.

18. Holmström M, el Azazi M, Kugelberg U. Ophthalmological long-term follow up of preterm infants: a population based, prospective study of the refraction and its development. Br J Ophthalmol. 1998;82(11): $1265-1271$

19. Yang CS, Wang AG, Shih YF, Hsu WM. Astigmatism and biometric optic components of diode laser-treated threshold retinopathy of prematurity at 9 years of age. Eye (Lond). 2013;27(3):374-381.

20. Davitt BV, Dobson V, Quinn GE, et al. Astigmatism in the Early Treatment for Retinopathy Of Prematurity Study: findings to 3 years of age. Ophthalmology. 2009;116(2):332-339.

21. Davitt BV, Quinn GE, Wallace DK, et al. Astigmatism progression in the early treatment for retinopathy of prematurity study to 6 years of age. Ophthalmology. 2011;118(12):2326-2329.

22. McLoone EM, O'Keefe M, McLoone SF, Lanigan BM. Long-term refractive and biometric outcomes following diode laser therapy for retinopathy of prematurity. J AAPOS. 2006;10(5):454-459.

23. Ospina LH, Lyons CJ, Matsuba C, Jan J, McCormick AQ. Argon laser photocoagulation for retinopathy of prematurity: long-term outcome. Eye (Lond). 2005;19(11):1213-1218.

24. Holmström G, el Azazi M, Kugelberg U. Ophthalmological follow up of preterm infants: a population based, prospective study of visual acuity and strabismus. Br J Ophthalmol. 1999;83(2):143-150.
Clinical Ophthalmology

\section{Publish your work in this journal}

Clinical Ophthalmology is an international, peer-reviewed journal covering all subspecialties within ophthalmology. Key topics include: Optometry; Visual science; Pharmacology and drug therapy in eye diseases; Basic Sciences; Primary and Secondary eye care; Patient Safety and Quality of Care Improvements. This journal is indexed on Submit your manuscript here: http://www.dovepress.com/clinical-ophthalmology-journal

\section{Dovepress}

PubMed Central and CAS, and is the official journal of The Society of Clinical Ophthalmology (SCO). The manuscript management system is completely online and includes a very quick and fair peer-review system, which is all easy to use. Visit http://www.dovepress.com/ testimonials.php to read real quotes from published authors. 